Palabras mudas: guerras, comisiones de la verdad y derechos humanos en América Latina 


\title{
Declaración en el acto de creación de la Comisión de la Verdad en la Universidade de São Paulo (USP)
}

\author{
Statement in the Act of Creation of the Truth Commission \\ at the Universidade de São Paulo (USP) \\ Declaração no fato de criação da Comissão da Verdade \\ da Universidade de São Paulo (USP)
}

\section{Marilena Chaui}

UNIVERSIDADE DE SÃO PAULO, BRASIL

Profesora del Departamento de Filosofía de la Facultad de Filosofía, Letras y

Ciencias Humanas de la Universidade de São Paulo. Doctora en Filosofía

de la Universidade de São Paulo. Ha publicado Convite à filosofia (Atica, 1994), O ser humano é um ser social (Martins Fontes, 2013), Between

Conformity and Resistence. Essays on Politics, Culture and the State (Palgrave

Macmillan, 2011), Simulacro e poder: uma análise da mídia (Fundação

Perseu Abramo, 2010), Cultura e democracia. O discurso competente e outras

falas (Editora Cortez, 2006). Correo electrónico: mchaui@ajato.com.br

Ensayo

Documento accesible en línea desde la siguie nte dirección: http://revistas.javeriana.edu.co

doi:10.11144/Javeriana.CL18-36.dacc

Traducción de Jeffrey Cedeño, Renata Pontes y Diana Catalina Hernández. Jeffrey Cedeño es profesor del Departamento de Literatura de la Pontificia Universidad Javeriana, Bogotá, y editor de la revista del departamento, Cuadernos de Literatura. Ha publicado varios artículos en revistas especializadas y coordinado números monográficos para Revista Iberoamericana, RCLL, Estudios, Universitas Humanistica, ReVista. Harvard Review of Latin America, Cultural Studies, Iberoamericana (Alemania), entre otras; correo electrónico: jcedeno@javeriana.edu.co. Renata Pontes es graduada en Comunicación Social-Periodismo en Brasil. Cursó la Maestría en Literaturas Española y Latinoamericana en la Universidad de Buenos Aires (UBA) y actualmente es estudiante del programa de Doctorado en Literatura de la Pontificia Universidad Católica de Chile. Desde 2012 viene trabajando como traductora de textos académicos y literarios al portugués y al español. Correo electrónico: rpontes@uc.cl. Diana Catalina Hernández es Profesional en Estudios Literarios de la Pontificia Universidad Javeriana, Bogotá, y Filósofa de la Universidad Nacional de Colombia, Bogotá. Correo electrónico: dchernandezq@gmail.com

Cómo citar este ensayo:

Chaui, Marilena. "Declaración en el acto de creación de la Comisión de la Verdad en la Universidade de São Paulo (USP)". Cuadernos de Literatura 18.36 (2014): 135-140. http://dx.doi.org/10.11144/Javeriana.CL18-36.dacc 
BuEnas noches a todos y a todas. Quiero iniciar mi discurso con dos presentaciones. La primera es la de Heleny Guariba. Heleny y yo estudiamos juntas, precisamente fue ella quien me presentó a mi novio, con quien me casé un tiempo después. Estuve con Heleny la víspera del día de su arresto; charlamos durante varias horas en mi casa e hicimos algunos planes para el día siguiente, pero nunca más la volví a ver. La segunda presentación es la de otro colega, Luiz Roberto Salinas. Luiz Roberto no murió en la prisión, pero sin duda murió por las secuelas de su encarcelamiento. A Luiz Roberto lo encarcelaron y lo torturaron, si bien en aquella época, a finales de los años 70, ya no militaba en ningún movimiento o grupo. Había militado mucho antes, a la altura de 1964. La esposa de Luiz Roberto era periodista y por esos días había publicado un reportaje. Como los policías, los militares, no entendieron algunas de las palabras del reportaje, lo interpretaron como un código cifrado. Allanaron el apartamento de Luiz Roberto, pero como su esposa no se encontraba en ese momento, lo apresaron y lo torturaron en el "Pau de arara"l días sin fin para que confesara cuál era la clave. No había código alguno, no había nada que descifrar, nada, pero lo despedazaron, lo devastaron física y psíquicamente. Transcurrieron muchos años para que pudiera recuperarse, aunque nunca lo consiguió realmente. Sufrió una trombosis en sus dos piernas y tuvieron que amputarle los dedos de los pies. Murió con un síncope. Es claro que la tortura lo privó de la vida. Luiz Roberto era un gran amigo, un amigo del corazón. Entramos juntos al Departamento de Filosofía y juntos nos titulamos como profesores de la USP.

Me gustaría contarles cómo eran los días en el campus de la USP durante 1969, después de diciembre de 1968, cuando fue promulgado el Acto Institucional $5(\mathrm{AI} 5)^{2}$. Uno venía para acá y no tenía ninguna garantía de no ser encarcelado y torturado; por lo tanto, no sabía si los alumnos estarían en la clase y, cuando nos dábamos cuenta de que algunos no estaban, no se osaba preguntar si se habían exiliado, si estaban presos o muertos. Lo mismo sucedía

1 Instrumento de tortura consistente en un rodillo del que se cuelga a la víctima por las rodillas y los codos. En esas condiciones, se le aplica corriente eléctrica en diversas partes del cuerpo. (Nota de los traductores).

2 El Ato Institucional n. ${ }^{\circ}$ 5, publicado el 13 de diciembre de 1968, durante el gobierno del general Costa e Silva, fue la expresión más taxativa de la dictadura militar brasileña. Estuvo vigente hasta diciembre del 1978 y motivó una serie de acciones arbitrarias de efecto duradero. Definió el momento más doloroso del régimen militar dando poder de excepción a los gobernantes para punir arbitrariamente a los considerados "enemigos" de la dictadura. (Nota de los traductores). 
con los colegas. Teníamos a los funcionarios del Dops ${ }^{3}$ camuflados como civiles en los salones de clase e informantes en la sala de los profesores y en el café. Nos vigilaban día y noche.

Recuerdo que, en 1975, la Universidade Estadual de Campinas (Unicamp) organizó un congreso internacional de historiadores, e invitó a Eric Hobsbawn, a E. P. Thompson, en fin, a la izquierda internacional. Los brasileños leyeron sus ponencias, pero los invitados extranjeros no tardaron en decirnos: "no logramos comprender nada de lo que ustedes dicen, no entendimos sus trabajos, pero sobre todo no entendimos los debates entre ustedes". Entonces, nos dimos cuenta de que utilizábamos un lenguaje cifrado, precisamente para evitar que nos encarcelaran. La izquierda académica tuvo que crear un dialecto, un lenguaje propio en el cual decía todo lo que quería decir, y no decía nada que fuese comprensible más allá de su propio círculo. Era ciertamente una forma de autodefensa y, también, una forma de continuar produciendo, pensando y discutiendo ideas. Al mismo tiempo, este gesto nos enclaustró en un círculo donde nosotros nos identificábamos con nosotros mismos. Considero importante que la Comisión de la Verdad testifique que, durante muchos años, nos vimos forzados a crear un dialecto, a crear un conjunto de normas, de reglas y de comportamientos frente a los otros, para evitar la cárcel, la tortura, la muerte.

Acostumbro a decirles a los jóvenes que ellos desconocen lo que es el miedo, el terror. Salir y no saber si se va a regresar; salir y no saber si, al regresar, los hijos estarán en casa; salir y no saber si se va a encontrar a su compañero; ir a la escuela y no saber si estarán los alumnos, los colegas. Uno no sabe nada. Acecha entonces una amenaza aterradora sobre quién tiene el control de nuestra vida, que es como decir el control de nuestra muerte. Así fue la USP durante casi diez años, todos los días. Además, las personas iban desapareciendo...

Me hubiese gustado que Eunice Durham estuviera aquí. Cuando Eunice formó parte de la Associação dos Docentes da USP (Adusp), en la gestión de Modesto Varvalhosa, escribió el llamado "Libro negro de la USP", en el que relata cómo se hicieron las anulaciones. Las anulaciones no vinieron de las alturas del poder. No.

3 El término "Dops" significa Departamento de Ordem Política e Social. Fue creado para mantener el control de los ciudadanos y vigilar las manifestaciones políticas en la dictadura, después de 1964. El Dops perseguía, sobre todo, las actividades intelectuales, sociales, políticas y partidarias de carácter comunista. (Nota de los traductores).

4 Este libro es una reconstitución de los hechos ocurridos en la Universidade de São Paulo después de 1964 que culminaron en renuncias y jubilaciones forzadas entre los profesores. La amplitud, el carácter insidioso y los efectos destructores de todo este proceso todavía no son de conocimiento general en Brasil. (Nota de los traductores). 
Las congregaciones de cada instituto y de cada facultad se encargaron de denunciar, delatar y ejecutar las anulaciones. La Comisión de la Verdad precisa dejar muy claro lo siguiente: no fueron fuerzas externas las que hicieron las anulaciones, tampoco los militares; fueron nuestros colegas, los civiles académicos dentro de la universidad quienes hicieron una limpieza de sangre. Es una cosa siniestra. Esos mismos colegas se encontraban impávidos cuando comenzó la lucha por la vuelta de la democracia, cuando comenzaron las huelgas en el $\mathrm{ABC}^{5}$, cuando se iniciaron las luchas por las elecciones libres y directas. Asistí a las asambleas de la Adusp y del Directório Central dos Estudantes (DCE), y me encontraba justo al lado de muchos de ellos, estaban ahí para defender el retorno de la democracia, cuando habían apoyado la dictadura. Esto no puede quedar en blanco, en el olvido. Una Comisión de la Verdad tiene que decir esto.

Y me gustaría también, como una contribución al trabajo de la Comisión de la Verdad, retomar lo ya mencionado: el hecho de que la estructura de nuestra universidad es la misma que la dictadura introdujo en el Brasil - por medio del Ministério da Educação (MEC) y del acuerdo MEC-USAID. En la USP, más que en otras universidades, este modelo logró cristalizarse. La reforma universitaria implantó la idea de créditos, la idea de cursos obligatorios y cursos optativos. Como la sustentación ideológica de la dictadura era la clase media urbana, era preciso compensar a la clase media por la falta de poder económico y político y la compensación se dio por medio del prestigio del título universitario. Así se erigió la industria del examen de admisión en la universidad (que se llama Vestibular en Brasil), implantado por decreto. Es decir, la universidad que ustedes frecuentan, la universidad que ustedes cursan, la universidad en la que nosotros damos clase, es una universidad que fue estructurada a partir del Acto Institucional 5. Otras universidades contaron con fuerza suficiente entre sus profesores y estudiantes para derribar muchas cosas. Sin embargo, no pudieron hacer lo mismo con la estructura curricular; continuamos en Brasil con cursos obligatorios, optativos, créditos, asistencia... La introducción de los créditos significó la escolarización de la vida universitaria. En una universidad uno debe cursar, a lo sumo, dos o tres materias y cada una de ellas debe contar con dos a tres horas de clase por semana. Lo ideal son dos materias, cada una con dos horas semanales para que uno trabaje lo que se expuso y discutió en clase, para que vaya a las bibliotecas

5 ABC Paulista, Região do Grande ABC o solamente ABC es una región tradicionalmente industrial del estado de São Paulo. Parte de la Região Metropolitana de São Paulo cuenta con identidad propia. La sigla se refiere a las tres ciudades que originalmente conformaban la región: Santo André (A), São Bernardo do Campo (B) y São Caetano do Sul (C). (Nota de los traductores). 
y laboratorios, haga investigaciones y tenga efectivamente una vida universitaria. La reforma que implantó la dictadura, al escolarizar la universidad, no pudo menos que transformarla en una secundaria avanzada, en una escuela avanzada. La Comisión de la Verdad tiene que evidenciar todo esto, tiene que revelar las fechas de publicación de los decretos, las fechas de implantación de estas estructuras y quién las implantó. Nada de esto puede pasar inadvertido.

Otra cuestión muy importante es que, en aquella época, las contrataciones de los jóvenes profesores no eran una responsabilidad de los departamentos, ni de los institutos, sino de la Rectoría. ¿Cuál era el proceder de la Rectoría? $\mathrm{Al}$ recibir el proceso de contratación, lo remitía al Dops para que la policía enviara la ficha policial del profesor y saber si había militado en algún movimiento. La Rectoría solicitaba la ficha policial, es decir, la ficha política del profesor. A partir de ese informe aprobaba o no la contratación. Cuando fui jefa del Departamento de Filosofía, tramité el proceso de contratación de un joven profesor, pero no se formalizaba. Los recaudos estaban en la Rectoría y pedí información de por qué no se había efectuado la contratación. Me llevaron de una oficina a otra, y luego a otra, y nadie respondía. Finalmente, terminé en una sala justo al lado de la oficina del Rector. Esta sala no tenía ventanas, tenía tan solo una puerta y dos sillas con una mesita. Allí, un señor, un civil, canoso, muy bien educado, pidió que tomara asiento y me dijo: "Le voy a explicar a la profesora que esta sala no existe, yo no existo y la conversación que vamos a tener nunca sucedió. El profesor no puede ser contratado porque estuvo en un encuentro estudiantil terrorista, aquí está el informe". Y fue cuando vi: estaba todo anotado en lápiz, con las informaciones sobre él venidas del Dops. Y todavía me dijo: "Yo sé que él era un lambari", sé que no es un peligro para la seguridad nacional, pero tiene esa ficha y no puede ser contratado". Y fue contratado. Ustedes pueden imaginar el barullo, todo el escándalo que hicimos y el riesgo que corrimos. Pero era una intimidación directa, frontal, sin tapujos, que quería decir: "Yo puedo, yo tengo el poder, yo hago lo que quiero, ustedes deben seguir mis órdenes".

La actual estructura de la Universidade de São Paulo, concebida por la dictadura a partir del Acto Institucional número 5, es algo que debe ser explicitado y analizado si queremos democratizar la universidad. Para democratizar nuestra universidad, tenemos que desmontar lo que fue implantado al final de los años

6 Lambari es una especie de pescado. En Brasil, se usa la expresión "peixe pequeno" para referirse a los que no son los verdaderos responsables por un hecho social. (Nota de los traductores). 
sesenta y en el transcurso de los años setenta. Es una tarea inmensa y urgente que debe realizarse. ¿Y por qué debemos hacerla? Porque, en este momento, cuando existe en el estado de São Paulo la hegemonía de un pensamiento privatizador y neoliberal, la universidad está siendo dirigida de acuerdo con estos principios por el actual Rector. Además, este Rector fue formado como dirigente en el "caldo" de la dictadura. Por lo tanto, es esa forma de gestión la que explica esa cosa increíble - que acaso hizo la dictadura - de poner la policía adentro del campus para golpear alumnos.

Y, para concluir, me dispongo a hacer mi declaración a la Comisión de la Verdad. Pienso, como los que me antecedieron, que debe ser considerado un largo periodo y, como se trata de la Comisión de la Verdad, en el caso de la Universidade de São Paulo, es preciso contar no solo las historias ligadas a la violencia de Estado, al terrorismo de Estado sobre profesores y alumnos, sino también la manera por la cual la universidad fue estructurada para ser un órgano de la violencia, un órgano del autoritarismo. La USP fue estructurada con la racionalidad de la dictadura y es por eso que ella es autoritaria. Es eso lo que la Comisión de la Verdad debe evidenciar. Y Salinas, presente; Heleny, presente. 